\title{
Pathophysiology of Diabetes In The Elderly
}

\author{
Graydon S. Meneilly
}

Division of Geriatric Medicine, Department of Medicine, The University of British Columbia, Vancouver BC, Canada

\section{Key messages}

- Lifestyle factors play a major role in diabetes in the elderly.

- Diabetes in the elderly is metabolically distinct.

- Elderly patients with diabetes have an increase incidence of severe or fatal hypoglycemia.

\subsection{Introduction}

In the past, numerous studies have been conducted to investigate the pathogenesis of type 2 diabetes [1]. Although, unfortunately, elderly patients were systematically excluded from these studies, we have more recently started to study, in systematic fashion, the pathophysiological alterations that occur in elderly patients with diabetes. These studies, the details of which will be reviewed in the following sections, suggest that there are many ways in which diabetes in the elderly is unique. Some of the factors that contribute to the high prevalence diabetes in the elderly are shown schematically in Figure 1.1.

\subsubsection{Genetic factors}

There are several lines of evidence which suggest that there is a strong genetic component to diabetes in the

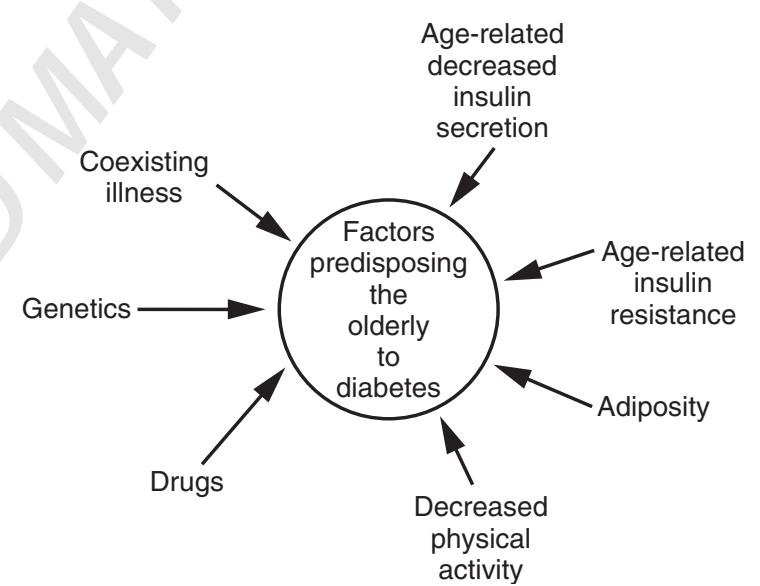

Figure 1.1 Factors that contribute to the high prevalence of diabetes in the elderly. Reproduced with permission from Halter, J.B., Carbohydrate metabolism, in: E.J. Masoro (ed.), Handbook of Physiology, Volume on Aging. New York, Oxford University Press Inc., 1995, p. 119.

elderly, although the specific genes responsible have yet to be defined [2]. If you have a family history of type 2 diabetes, you are much more likely to develop the disease as you age [3]. Diabetes is much more common in the elderly in certain ethnic groups [4], while the likelihood that an elderly identical twin will develop diabetes if their sibling is affected is over $80 \%$. 
Even in elderly identical twins discordant for type 2 diabetes, the unaffected siblings clearly have evidence of abnormal glucose metabolism [5].

\subsubsection{Age-related changes in carbohydrate metabolism}

The progressive alterations in glucose metabolism that occur with age explain why genetically susceptible older individuals may not develop diabetes until late in life. Pathogenic mechanisms which contribute to the glucose intolerance of aging include alterations in glucose-induced insulin release and resistance to insulin-mediated glucose disposal [6]. The results of early investigations suggested that glucose-induced insulin release was normal in the elderly. However, more recent studies enrolling large numbers of carefully characterized healthy young and old subjects have demonstrated definable alterations in glucose-induced insulin release in the aged $[6,7]$. Of note, the magnitude of the decrement in insulin secretion is more apparent in response to oral than to intravenous glucose [6]. This may be due, in part, to a decreased beta cell response to the incretin hormones (see below). As with many hormones, insulin is secreted in a pulsatile fashion. Normal aging is also associated with subtle alterations in pulsatile insulin release, which further contribute to age-related changes in glucose metabolism [8]. Elevated levels of proinsulin, which suggest disordered insulin processing, predict the subsequent development of type 2 diabetes in elderly subjects [9]. Thus, it is clear that alterations in glucose-induced insulin release are an important component of the changes in carbohydrate metabolism with aging. However, the most important pathogenic mechanism underlying the glucose intolerance of aging is resistance to insulin-mediated glucose disposal $[6,10]$. Debate persists as to whether the insulin resistance of the elderly is intrinsic to the aging process itself, or is the result of lifestyle factors commonly associated with aging. The consensus of opinion is that the aging process itself is the most important cause of insulin resistance, although lifestyle changes (see below), are clearly an important contributing factor.

\subsubsection{Lifestyle and environmental factors}

Despite the strong genetic component, it is abundantly clear that various environmental and lifestyle factors can increase or decrease the likelihood that a genetically susceptible individual will develop the disease in old age. Many older people have coexisting illnesses and take multiple drugs (e.g., thiazide diuretics), which can allow a latent abnormality in glucose metabolism to develop into full-blown diabetes [11, 12]. Obesity, especially with a central distribution of body fat, and a reduction in physical activity occur progressively with aging, and both of these factors are associated with abnormal carbohydrate metabolism [12-17].

The above information suggests that lifestyle modifications may be of value in the prevention of type 2 diabetes in the elderly, even in patients with a strong family history of the disease. Indeed, the Diabetes Prevention Program found that a combined lifestyle intervention consisting of weight loss and increased physical activity was effective in reducing the incidence of diabetes in elderly patients with impaired glucose tolerance [18].

\subsection{Diet and diabetes in the elderly}

The results of large epidemiologic studies have shown that diabetes is more likely to develop in older patients who have a diet that is high in saturated fats and simple sugars and low in complex carbohydrates [13, 19-21]. Moderate alcohol consumption may protect against diabetes in elderly women [22]. It has been suggested that deficiencies of trace elements or vitamins may contribute to the development or progression of diabetes in younger subjects, and it is increasingly recognized that the same may be true in the elderly $[12,21]$. Elderly patients with diabetes have exaggerated free radical production, and administration of the antioxidant vitamins $\mathrm{C}$ and $\mathrm{E}$ to these patients improves both insulin action and metabolic control [23, 24]. Many elderly patients with diabetes are deficient in magnesium and zinc, and supplements of zinc and magnesium can improve glucose metabolism in these patients $[25,26]$. Increased dietary iron may be associated with an increased risk of diabetes in aged individuals [20, 27]. Although chromium deficiency has been shown to cause abnormalities in glucose metabolism in animals and younger patients, there is no evidence to date that chromium supplements will improve glucose tolerance in the elderly. In summary, there is increasing evidence to suggest that dietary abnormalities may contribute to the pathogenesis of diabetes in the elderly, and that dietary modifications may be of therapeutic benefit in these patients. 


\subsection{Other factors}

The presence of inflammation, as evidenced by levels of proinflammatory cytokines such as tumour necrosis factor- $\alpha$ (TNF- $\alpha$ ) and C-reactive protein (CRP), is associated with an increased risk of diabetes in the elderly [28-31]. Higher levels of adiponectin (an adipocytokine that increases insulin sensitivity) are associated with a reduced incidence of diabetes in the aged [29, 32]. Sex steroid hormone levels also appear to be related to the development of diabetes in the elderly $[33,34]$. In particular, higher testosterone levels in women and lower levels in men appear to be associated with an increased incidence of diabetes.

\subsection{Metabolic alterations}

The metabolic alterations which occur in middle-aged subjects with type 2 diabetes have been extensively characterized [1]. When compared to age- and weightmatched controls, both lean and obese middle-aged subjects have elevated fasting hepatic glucose production, a marked resistance to insulin-mediated glucose disposal, and a profound impairment in glucose-induced pancreatic insulin release.

Recently, metabolic factors have been characterized in lean and obese elderly patients with diabetes [35-38]. These studies have demonstrated some surprising differences in the metabolic profile between middle-aged and elderly subjects. In contrast to younger subjects, fasting hepatic glucose production is normal in both lean and obese elderly subjects (Figure 1.2). Similar to younger subjects, lean elderly patients have a profound impairment in pancreatic insulin secretion but, in contrast to the young, these patients have minimal resistance to insulin-mediated glucose disposal (Figures 1.3 and 1.4). In contradistinction to the young, obese elderly subjects have relatively preserved glucose-induced insulin secretion (see Figure 1.3), although pulsatile insulin secretion is clearly altered [8]. Similar to the young however, these patients have a marked resistance to insulin-mediated glucose disposal (Figure 1.4). In summary, the principal defect in lean elderly subjects is impaired glucose-induced insulin release, while the principal defect in obese patients is resistance to insulin-mediated glucose disposal.

One of the most interesting findings of these studies was that the ability of insulin to enhance blood flow

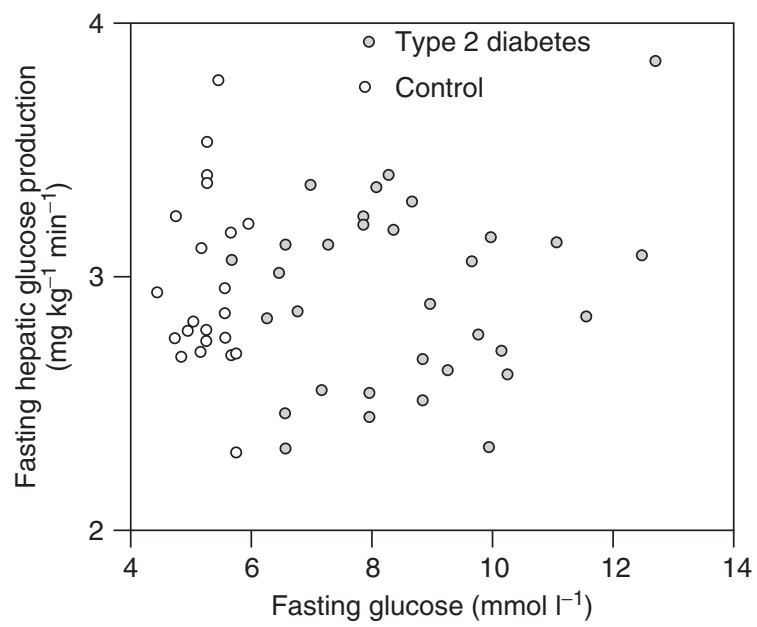

Figure 1.2 Fasting hepatic glucose production in relation to fasting glucose levels in healthy elderly controls and elderly patients with diabetes. Hepatic glucose production was measured by infusing radioactive glucose tracers.
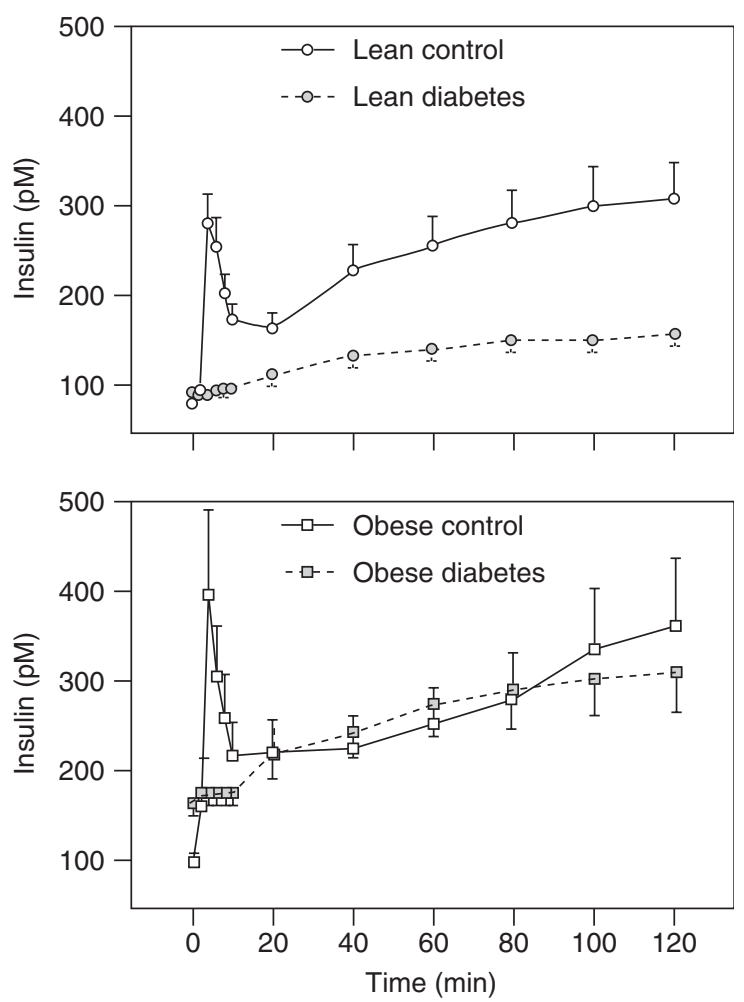

Figure 1.3 Glucose-induced insulin release in healthy elderly controls and elderly patients with diabetes. Insulin values were measured at glucose levels approximately $5 \mathrm{mmol} \mathrm{I}^{-1}$ above fasting levels. 


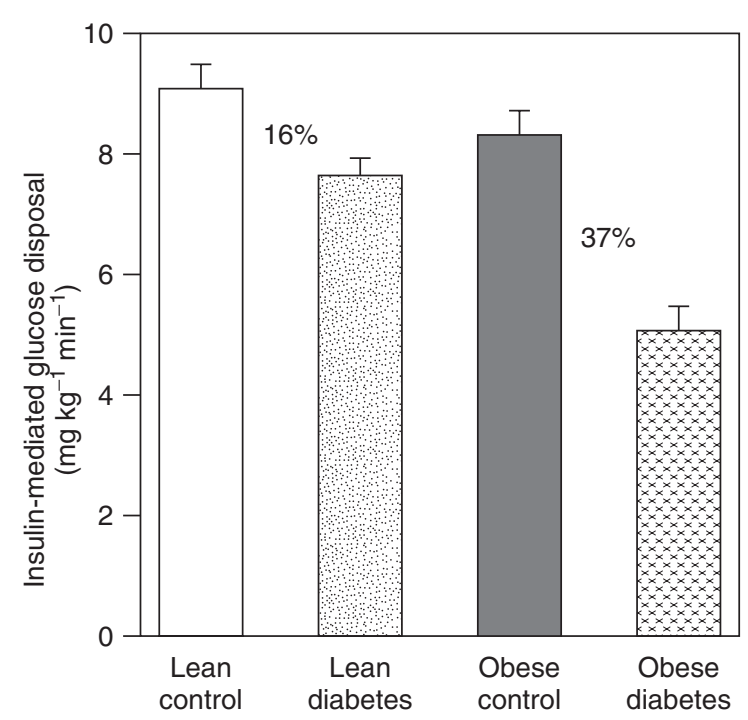

Figure 1.4 Insulin-mediated glucose disposal rates in healthy elderly controls and elderly patients with diabetes. Glucose disposal rates were measured utilizing the euglycaemic clamp technique. In this technique, insulin is infused to achieve levels occurring after a meal, and glucose is infused simultaneously to prevent hypoglycaemia.

was markedly reduced in obese, insulin-resistant older patients (Figure 1.5) [37]. Insulin-mediated vasodilation is thought to account for about $30 \%$ of normal glucose disposal, presumably because it increases the delivery of insulin and glucose to muscle tissue. Indeed, it has been demonstrated that angiotensinconverting enzyme (ACE) inhibitors may improve insulin sensitivity in elderly patients with diabetes and hypertension [39]. This suggests that drugs which enhance muscle blood flow may prove to be valuable adjuncts in the future for the therapy of elderly patients with diabetes.

It has been known for a number of years that autoimmune phenomena play a pivotal role in the beta-cell failure that occurs in patients with type 1 diabetes [40]. It is also increasingly recognized that a subset of middle-aged patients with type 2 diabetes have a form of diabetes that is characterized by beta-cell failure, and these patients often have high titres of islet cell antibodies and antibodies to glutamic acid decarboxylase (GAD), similar to younger patients with type 1 diabetes. These patients have been said to have LADA (latent autoimmune diabetes in adults) [41-47]. It is tempting to speculate that autoimmune phenomena contribute to the profound impairment in

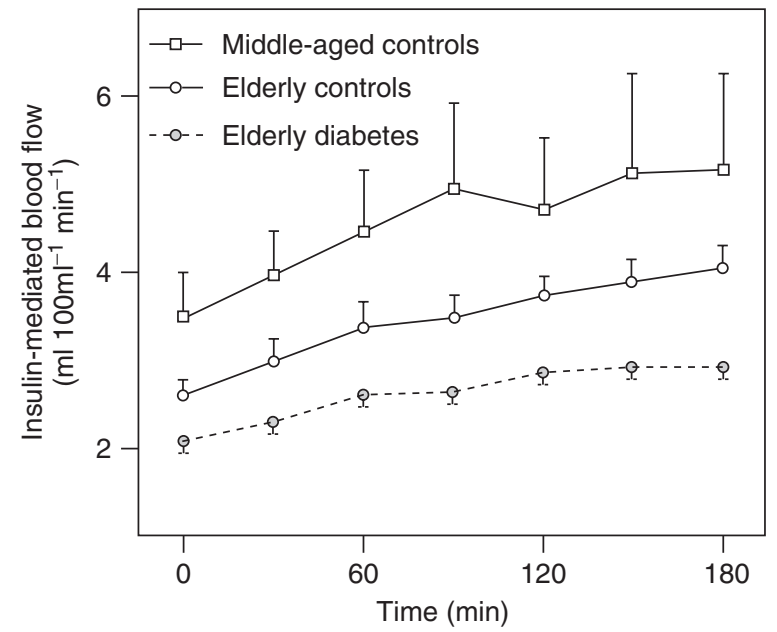

Figure 1.5 Insulin-mediated blood flow in obese middle-aged controls and obese elderly controls and patients with diabetes. Blood flow was measured in the calf during euglycaemic clamp studies utilizing venous occlusion plethysmography.

glucose-induced insulin secretion seen in lean older patients with type 2 diabetes. However, the clinical significance of elevated antibodies in the elderly is less certain. Some studies have found that elderly patients with diabetes who are positive for GAD have impaired beta-cell function relative to controls without these antibodies, but others have not [41, 48]. It has been suggested that screening for these auto-antibodies should be performed in elderly patients with impaired glucose tolerance (IGT) and newly diagnosed diabetes, in order to help predict which patients will develop islet cell failure. Although this is a compelling idea, we should only begin widespread screening when randomized studies have demonstrated that early intervention will protect the beta cells and reduce the need for insulin therapy [45-47]. Thus, it is unclear at present whether the measurement of auto-immune parameters can be used to predict future insulin requirements in the aged, or whether elderly patients with these abnormalities should be treated with therapies designed to modify autoimmune destruction of the pancreas.

Based on the above information, it is believed that the therapeutic approach to diabetes in the elderly should be different. In middle-aged patients, many endocrinologists recommend that patients be treated with drugs that both stimulate insulin secretion and improve insulin sensitivity, on the assumption that most patients have multiple metabolic problems. However, in 
lean elderly subjects, the principal defect is an impairment in glucose-induced insulin secretion, and the main approach should be to administer secretogogues to stimulate insulin secretion, or to administer exogenous insulin. In obese elderly patients, the principal defect is insulin resistance; hence, patients should be treated initially with drugs that enhance insulin-mediated glucose disposal, such as metformin.

\subsubsection{The incretin pathway}

The enteroinsular axis refers to hormones released from the gut in response to nutrient ingestion that result in enhanced glucose-induced insulin release, known as the 'incretin effect'. The most important incretin hormones are glucose-dependent insulinotropic polypeptide (GIP) and glucagon-like peptide 1 (GLP-1). Although, both basal and glucose-stimulated GIP and GLP-1 levels have been found to be unchanged or to be increased in healthy elderly subjects when compared to young controls, GIP and GLP-1 secretion is clearly enhanced in the elderly patient with diabetes $[49,50]$. In addition, the levels of dipeptidyl peptidase IV (DPIV), the enzyme that breaks down GIP and GLP-1, is progressively reduced with aging and diabetes. Beta-cell responses to GIP are reduced in normal elderly subjects and are absent in elderly patients with diabetes $[51,52]$. In contrast, beta-cell responses to GLP-1 are preserved in the elderly patient with diabetes [53]. These data suggest that GLP-1 and its analogues may prove to be useful therapeutic options in the elderly, but that agents which prevent the breakdown of GLP-1, such as DPIV inhibitors, may be less effective.

\subsubsection{Glucose effectiveness or non-insulin-mediated glucose uptake}

It has been recognized for many decades that insulin is an important hormone involved in the uptake of glucose into cells. It has been demonstrated that glucose can stimulate its own uptake in the absence of insulin [54], an effect which is known as 'glucose effectiveness' or non-insulin-mediated glucose uptake (NIMGU). Under fasting conditions, approximately $70 \%$ of glucose uptake occurs via glucose effectiveness, primarily in the central nervous system. After a meal, approximately $50 \%$ of glucose uptake in normal subjects occurs via NIMGU, with the bulk occurring in skeletal muscle. Because many middle-aged subjects with diabetes are insulin-resistant, it has been suggested that up to $80 \%$ of postprandial glucose uptake in these patients may occur via glucose effectiveness. At the present time it is uncertain whether defects in NIMGU contribute to elevated glucose levels in middle-aged patients with diabetes, as studies which have evaluated this parameter in these patients have provided inconsistent results.

It has been shown previously in healthy elderly subjects that glucose effectiveness is impaired during fasting, but is normal during hyperglycaemia [55]. Recently, it was demonstrated that elderly patients with diabetes have an even greater impairment in glucose effectiveness than healthy elderly subjects (Figure 1.6) [56]. Although the cause of this abnormality is uncertain, it may relate to a decreased ability of glucose to recruit glucose transporters to the cell surface in these patients.

In the future, this metabolic abnormality may prove to be of great therapeutic relevance to the elderly. In younger patients, exercise, anabolic steroids and a reduction in free fatty acid levels have been shown to enhance glucose effectiveness [54]. Since we have shown that the incretin hormone GLP-1 may enhance NIMGU in elderly patients with diabetes [57], it is possible that future therapies for the elderly may be directed not only at increasing insulin secretion and reversing insulin resistance, but also at enhancing glucose effectiveness.

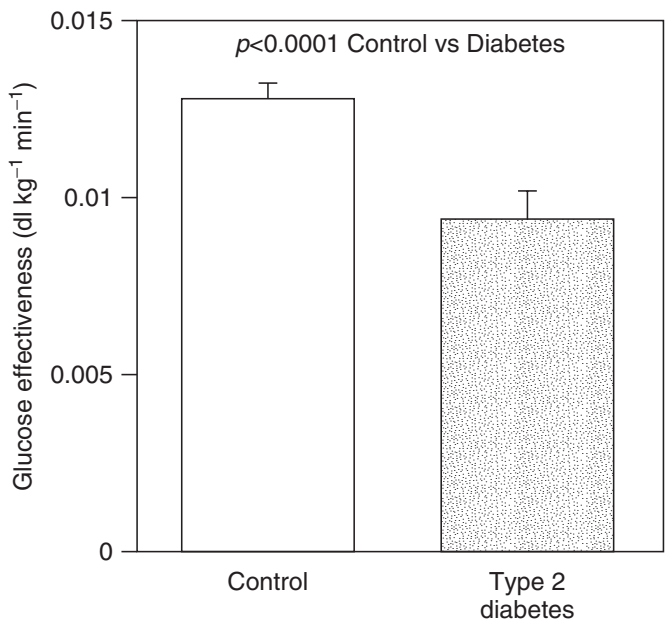

Figure 1.6 Glucose effectiveness in elderly controls and patients with diabetes. During these studies, insulin secretion was suppressed by infusing the somatostatin analogue octreotide. Glucose was then infused to assess glucose disposal in the absence of insulin. 


\subsection{Molecular biology studies}

At present, there is very little information available regarding molecular biological abnormalities that may be present in elderly patients with diabetes. The glucokinase gene controls the glucose sensor for the beta cell, and defects in this gene could lead to the impairment in glucose-induced insulin secretion that is present in lean elderly patients with diabetes. To date, evidence for mutations in this gene in elderly patients is conflicting [58, 59].

In skeletal muscle, insulin binds to its receptor, resulting in activation of the insulin receptor tyrosine kinase. Activation of this enzyme sets in motion a cascade of intracellular events which although at present is incompletely understood, results in the translocation of glucose transporters to the cell surface. In theory, a defect in any of these pathways could lead to insulin resistance. To date, these intracellular processes have been incompletely studied in elderly patients with diabetes, but the preliminary information suggests that while insulin receptor numbers and affinity are normal, the insulin receptor kinase activity may be defective [60]. Recent data have suggested that mitochondrial dysfunction contributes to insulin resistance in middle-aged patients with diabetes, and potentially also to impairments in glucose-induced insulin release [61]. Although normal aging is characterized by progressive mitochondrial dysfunction, to date no studies have been performed to assess mitochondrial function in elderly patients with diabetes [62-64]. Clearly, further studies are required to elucidate the subcellular defects that cause abnormal glucose metabolism in the elderly patient with diabetes.

\subsection{Glucose counter-regulation}

Numerous studies have demonstrated that elderly patients with diabetes, when compared to younger patients, have an increased frequency of severe or fatal hypoglycaemia [12, 65, 66]. Recently, several studies have evaluated glucose counter-regulation in elderly subjects in an attempt to determine the cause of the increased frequency of hypoglycaemia, and a number of important observations have emerged. It appears that many elderly patients with diabetes have not been educated about the warning symptoms of hypoglycaemia and, as a consequence, do not know how to interpret these symptoms when they occur [67].

The most important hormone in the defence against hypoglycaemia in normal subjects is glucagon. If glucagon responses are deficient, epinephrine becomes important, and growth hormone and cortisol come into play if hypoglycaemia is prolonged for several hours. The responses of both glucagon and growth hormone to hypoglycaemia are impaired in healthy elderly subjects, and to an even greater extent in older patients with diabetes (Figure 1.7) [68]. Yet, even when they are educated about the symptoms of hypoglycaemia, the elderly have a reduced awareness of the autonomic warning symptoms (sweating, palpitations, etc.) at glucose levels that would elicit a marked response in younger subjects. Consequently, the first symptoms of hypoglycaemia in the elderly are often neuroglycopenic. Finally, elderly patients have an impaired psychomotor performance during

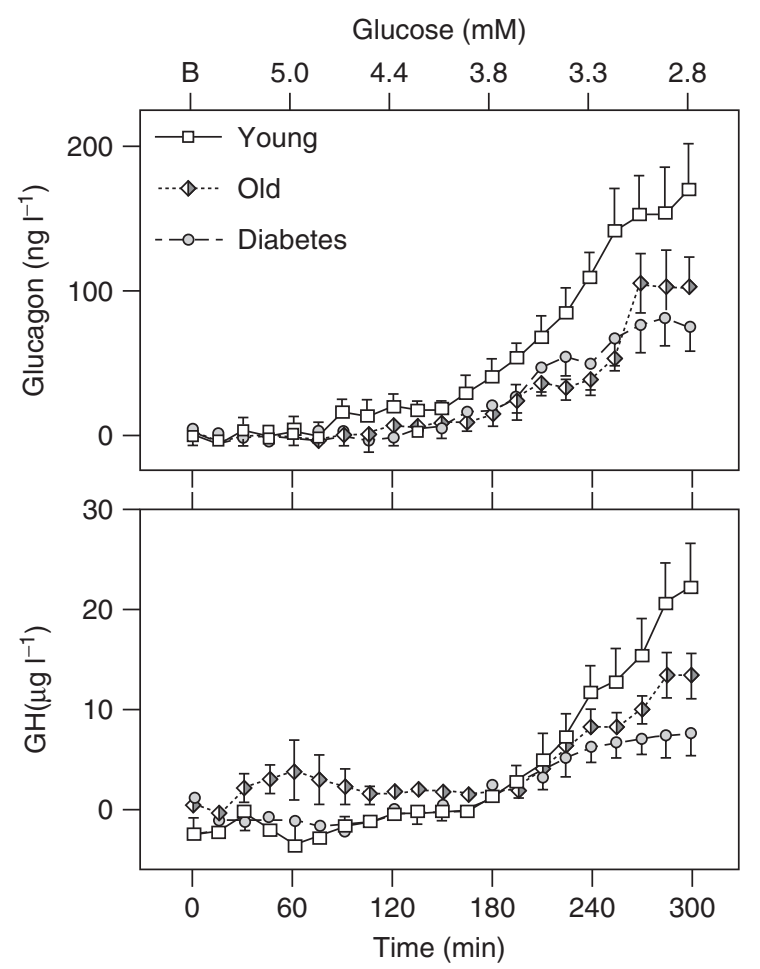

Figure 1.7 Glucagon and growth hormone responses to hypoglycaemia in healthy young, healthy old and elderly patients with diabetes. Controlled hypoglycaemia was induced using the glucose clamp technique. Glucose values at which hormone levels were measured are shown on the top $x$-axis. 
hypoglycaemia, which would prevent them from taking steps to return the blood glucose value to normal, even if they were aware that it was low. Thus, the increased frequency of hypoglycaemia in the elderly is due to a constellation of abnormalities, including a reduced knowledge and awareness of the warning symptoms, a decreased counter-regulatory hormone secretion, and an altered psychomotor performance.

The levels of pancreatic polypeptide (PP) are elevated during hypoglycaemia, and this response is mediated by the vagus nerve. The role of PP in normal glucose counter-regulation is uncertain, but in younger patients with diabetes a reduced PP response to hypoglycaemia is an early marker of autonomic insufficiency. Recently, it was found that although elderly patients with diabetes often have evidence of autonomic dysfunction, their PP responses to hypoglycaemia are normal [69]. Thus, PP responses to hypoglycaemia cannot be used to predict autonomic function in elderly patients.

Based on the above information, there are a number of interventions that can be proposed to prevent hypoglycaemic events in the elderly. First, it would seem prudent to educate elderly patients about the warning symptoms of hypoglycaemia so that they can appreciate them when they occur. Second, consideration should be given to the use of oral agents or insulin preparations that are associated with a lower frequency of hypoglycaemic events in the elderly.

\subsection{Conclusions}

In summary, diabetes in the elderly is caused by a combination of genetic and environmental factors superimposed on the normal age-related changes in carbohydrate metabolism. The metabolic alterations that occur in elderly patients with diabetes appear to be distinct from those that occur in younger patients. As we gain a greater appreciation of the pathophysiological abnormalities that occur in the elderly, we hope to be able to develop a more focused approach to therapy in this age group. It is only in this way that we will be able to better cope with the epidemic of diabetes in the elderly which will befall us in the coming decades.

\section{Acknowledgments}

The studies described in this chapter were supported by grants from the Canadian Institutes of Health Research and the Canadian Diabetes Association. I gratefully acknowledge the support of the Allan McGavin Geriatric Endowment at the University of British Columbia, and the Jack Bell Geriatric Endowment Fund at Vancouver Hospital and Health Science Centre.

I am especially indebted to my longstanding collaborators in this work, particularly Dr Dariush Elahi at Johns Hopkins Medical School and Dr Daniel Tessier at the University of Sherbrooke. I thank Rosemarie Torressani, Eugene Mar, Gail Chin and Christine Lockhart for technical assistance in conducting these studies.

\section{References}

1. DeFronzo, R.A. (1988) Lilly Lecture 1987. The triumvirate: $\beta$-cell, muscle, liver. A collusion responsible for NIDDM. Diabetes, 37, 667-87.

2. Kahn, C.R. (1984) Banting Lecture. Insulin action, diabetogenes, and the cause of type II diabetes. Diabetes, 43, 1066-84.

3. Morris, R.D. and Rimm, A.A. (1991) Association of waist to hip ratio and family history with the prevalence of NIDDM among 25,272 adult, white females. Am. J. Public Health, 81, 507-9.

4. Lipton, R.B., Liao, Y., Cao, G., Cooper, R.S. and McGee, D. (1993) Determinants of incident non-insulin-dependent diabetes mellitus among blacks and whites in a national sample. The NHANES 1 epidemiologic follow-up study. Am. J. Epidemiol., 138, 826-39.

5. Vaag, A., Henriksen, J.E., Madsbad, S., Holm, N. and Beck-Nielsen, H. (1995) Insulin secretion, insulin action, and hepatic glucose production in identical twins discordant for non-insulin-dependent diabetes mellitus. J. Clin. Invest., 95, 690-8.

6. Muller, D.C. Elahi, D., Tobin, J.D. and Andres, R. (1996) The effect of age on insulin resistance and secretion: a review. Semin Nephrol., 16, 289-98.

7. Iozzo, P., Beck-Nielsen, J., Laakso, M., Smith, U., Yki-Jarvinen, H. and Ferrannini, E. (1999) Independent influence of age on basal insulin secretion in non-diabetic humans. European group for the study of insulin resistance. Journal of Clinical Endocrinology and Metabolism, 84, 863-8.

8. Meneilly, G.S., Veldhuis, J.D. and Elahi, D. (2005) Deconvolution analysis of rapid insulin pulses before and after six weeks of continuous subcutaneous administration of GLP-1 in elderly patients with type 2 diabetes. Journal of Clinical Endocrinology and Metabolism, 90, 6251-6. 
9. Zethelius, B., Lithell, H.O., Hales, C.N. and Berne, C. (2004) Insulin resistance, impaired early insulin response, and insulin propeptides as predictors of the development of type 2 diabetes. Diabetes Care, 27, 1433-8.

10. Ferrannini, E. and the European Group for the Study of Insulin Resistance. (1996) Insulin action and age. Diabetes, 45, 949.

11. Pandit, M.K., Burke, J., Gustafson, A.B., Minocha, A. and Peiris, A.N. (1993) Drug-induced disorders of glucose tolerance. Ann. Intern. Med., 118, 529-39.

12. Meneilly, G.S. and Tessier, D. (2001) Diabetes in elderly adults. J. Gerontol., 56A, M5-13.

13. van Dam, R.M., Rimm, E.B., Willett, W.C. et al. (2002) Dietary patterns and risk for Type 2 diabetes mellitus in U.S. men. Ann. Intern. Med., 136, 201-9.

14. The DECODE-DECODA Study Group, on behalf of the European Diabetes Epidemiology Group and the International Diabetes Epidemiology Group. (2003) Age, body mass index and Type 2 diabetes - associations modified by ethnicity. Diabetologia, 48, 1063-70.

15. Goodpaster, B.H., Krishnaswami, S., Resnick, H. et al. (2003) Association between regional adipose tissue distribution and both Type 2 diabetes and impaired glucose tolerance in elderly men and women. Diabetes Care, 26, 372-9.

16. Meigs, J.B., Muller, D.C., Nathan, D.M. et al. (2003) The natural history of progression from normal glucose tolerance to Type 2 diabetes in the Baltimore longitudinal study of aging. Diabetes, 52, 1475-84.

17. Cassano, P.A., Rosner, B., Vokonas, P.S. and Weiss, S.T. (1992) Obesity and body fat distribution in relation to the incidence of non-insulin-dependent diabetes mellitus. American Journal of Epidemiology, 136, 1474-86.

18. Diabetes Prevention Program Research Group. (2002) Reduction in the incidence of Type 2 diabetes with lifestyle intervention or metformin. N. Engl. J. Med., 346, 393-403.

19. Feskens, E.J.M., Virtanen, S.M., Rasanen, L., Tuomilehto, J., Stengard, J., Pekkanen, J., Nissinen, A. and Kromhout, D. (1995) Dietary factors determining diabetes and impaired glucose tolerance. Diabetes Care, 18, 1104-12.

20. Song, Y., Manson, J.E., Buring, J.E. et al. (2004) A prospective study of red meat consumption and Type 2 diabetes in middle-aged and elderly women. Diabetes Care, 27, 2108-15.

21. Meyer, K.A., Kushi, L.H., Jacobs, D.R. et al. (2000) Carbohydrates, dietary fiber, and incident type 2 diabetes in older women. Am. J. Clin. Nutr., 71, 921-30.

22. Beulens, J.W.J., Stolk, R.P., Van der Schouw, Y.T., Grobbee, D.E., Hendriks, H.F.J. and Bots, M.L. (2005)
Alcohol consumption and risk of type 2 diabetes among older women. Diabetes Care, 28, 2933-8.

23. Paolisso, G., D'Amore, A., Galzerano, D., Balbi, V., Giugliano, D., Varricchio, M. and D’Onofrio, F. (1993) Daily vitamin E supplements improve metabolic control but not insulin secretion in elderly type II diabetic patients. Diabetes Care, 16, 1433-7.

24. Paolisso, G., D'Amore, A., Balbi, V., Volpe, C., Galzerano, D., Giugliano, D., Sgambato, S., Varricchio, M. and D'Onofrio, F. (1994) Plasma vitamin C affects glucose homeostasis in healthy subjects and in non-insulin-dependent diabetics. Am. J. Physiol., 266, E261-8.

25. Paolisso, G., Scheen, A., Cozzolino, D. et al. (1994) Changes in glucose turnover parameters and improvement of glucose oxidation after 4-week magnesium administration in elderly non-insulin-dependent (type II) diabetic patients. Journal of Clinical Endocrinology and Metabolism, 78, 1510-15.

26. Song, M.K., Rosenthal, M.J., Naliboff, B.D., Phanumas, L. and Kang, K.W. (1998) Effects of bovine prostate powder on zinc, glucose and insulin metabolism in old patients with non-insulin-dependent diabetes mellitus. Metabolism, 47, 39-43.

27. Lee, D.H., Folsom, A.R. and Jacobs, D.R. (2004) Dietary iron intake and Type 2 diabetes incidence in postmenopausal women: the Iowa Women's Health Study. Diabetologia, 47, 185-94.

28. Barzilay, J.I., Abraham, L., Heckbert, S. et al. (2001) The relation of markers of inflammation to the development of glucose disorders in the elderly. Diabetes, 50, 2384-9.

29. Kanaya, A.M., Harris, T., Goodpaster, B.H. et al. (2004) Adipocytokines attenuate the association between visceral adiposity and diabetes in older adults. Diabetes Care, 27, 1375-80.

30. Lechleitner, M., Herold, M., Dzien-Bischinger, C., Hoppichlert, F. and Dzien, A. (2002) Tumour necrosis factor-alpha plasma levels in elderly patients with Type 2 diabetes mellitus - observations over 2 years. Diabetic Medicine, 19, 949-53.

31. de Rekeneire, N., Peila, R., Ding, J., Kritchevsky, S.B., Colbert, L.H., Visser, M., Shorr, R.I., Kuller, L.H., Strotmeyer, E.S., Schwartz, A.V., Vellas, B. and Harris, T.B. (2006) Diabetes, hyperglycemia, and inflammation in older individuals. Diabetes Care, 29, 1902-8.

32. Snijder, M.B., Seidell, J.C., Heine, R.J., Bouter, L.M., Nijpels, G., Stehouwer, C.D.A., Funahashi, T., Matsuzawa, Y., Shimomura, I. and Dekker, J.M. (2006) Associations of adiponectin levels with incident impaired glucose metabolism and type 2 diabetes in older men and women. Diabetes Care, 29, 2498-503.

33. Oh, J.-Y., Barrett-Connor, E., Wedick, N.M. et al. (2002) Endogenous sex hormones and the development 
of Type 2 diabetes in older men and women: the Rancho Bernardo Study. Diabetes Care, 25, 55-60.

34. Golden, S.H., Dobs, A.S., Vaidya, D., Szklo, M., Gapstur, S., Kopp, P., Liu, K, and Ouyang, P. (2007) Endogenous sex hormones and glucose tolerance status in postmenopausal women. Journal of Clinical Endocrinology and Metabolism, 92 (4), 1289-95.

35. Arner, P., Pollare, T. and Lithell, H. (1991) Different aetiologies of type 2 (non-insulin-dependent) diabetes mellitus in obese and non-obese subjects. Diabetologia, 34, 483-7.

36. Meneilly, G.S., Hards, L., Tessier, D., Elliott, T. and Tildesley, H. (1996) NIDDM in the elderly. Diabetes Care, 19, 1320-75.

37. Meneilly, G.S. and Elliott, T. (1999) Metabolic alterations in middle-aged and elderly obese patients with type 2 diabetes. Diabetes Care, 22, 112-18.

38. Meneilly, G.S. and Elahi, D. (2005) Metabolic alterations in middle-aged and elderly lean patients with Type 2 diabetes. Diabetes Care, 28, 1498-9.

39. Paolisso, G., Gambardella, A., Verza, M., D’Amora, A., Sgambato, S. and Varricchio, M. (1992) ACEinhibition improves insulin-sensitivity in age insulinresistant hypertensive patients. J. Hum. Hypertens., 6, $175-9$.

40. Zimmet, P.Z. (1999) Diabetes epidemiology as a tool to trigger diabetes research and care. Diabetologia, 42, 499-518.

41. Monge, L., Brunot, G., Pinach, S., et al. (2004) A clinically orientated approach increases the efficiency of screening for latent autoimmune diabetes in adults (LADA) in a large clinic-based cohort of patients with diabetes onset over 50 years. Diabetic Medicine, 21, 456-9.

42. Barinas-Mitchell, E., Pietropaolo, S., Zhang, Y.-J. et al. (2004) Islet cell autoimmunity in a triethnic adult population of the Third National Health and Nutrition Examination Survey. Diabetes, 53, 1293-302.

43. Zinman, B., Kahn, S.E., Haffner, S.M. et al. (2004) Phenotypic characteristics of GAD antibody-positive recently diagnosed patients with Type 2 diabetes in North America and Europe. Diabetes, 53, 3193-200.

44. Pozzilli, P. and Di Mario, U. (2001) Autoimmune diabetes not requiring insulin at diagnosis (Latent autoimmune diabetes of the adult). Diabetes Care, 24, 1460-7.

45. Gale, E.A.M. (2005) Latent autoimmune diabetes in adults: a guide for perplexed. Diabetologia, 48, 2195-9.

46. Fourlanos, S., Dotta, F., Greenbaum, C.J., Palmer, J.P., Rolandsson, O., Colman, P.G. and Harrison, L.C. (2005) Latent autoimmune diabetes in adults (LADA) should be less latent. Diabetologia, 48, 2206-12.
47. Leslie, R.D.G., Williams, R. and Pozzilli, P. (2006) Clinical review: type 1 diabetes and latent autoimmune diabetes in adults: One end of the rainbow. Journal of Clinical Endocrinology and Metabolism, 91, 1654-9.

48. Meneilly, G.S., Tildesley, H., Elliott, T., Palmer, J.P. and Juneja, R. (2000) Significance of GAD positivity in elderly patients with diabetes. Diabetic Medicine, 17, 247-8.

49. Meneilly, G.S., Demuth, H.-U., McIntosh, C.H.S. and Pederson, R.A. (2000) Effect of ageing and diabetes on glucose-dependent insulinotropic polypeptide and dipeptidyl peptidase IV responses to oral glucose. Diabetic Medicine, 17, 346-50.

50. Korosi, J., McIntosh, C.H.S., Pederson, R.A., Demuth, H.-U., Habener, J.F., Gingerich, R., Egan, J.M., Elahi, D. and Meneilly, G.S. (2001) Effect of aging and diabetes on the enteroinsular axis. Journal of Gerontology, 56A, M575-9.

51. Meneilly, G.S., Ryan, A.S., Minaker, K.L. and Elahi, D. (1998) The effect of age and glycemic level on the response of the $\alpha$-cell to glucose-dependent insulinotropic polypeptide and peripheral tissue sensitivity to endogenously released insulin. Journal of Clinical Endocrinology and Metabolism, 83, 2925-31.

52. Elahi, D., McAloon-Dyke, M., Fukagawa, N.K., Meneilly, G.S., Sclater, A.L., Minaker, K.L., Habener, J.F. and Andersen, D.K. (1994) The insulinotropic actions of glucose-dependent insulinotropic polypeptide (GIP) and glucagon-like peptide-1 (7-37) in normal and diabetic subjects. Regul. Pept., 51, 63-74.

53. Meneilly, G.S., McIntosh, C.H., Pederson, R.A., Habener, J.F., Gingerich, R., Egan, J.M. and Elahi, D. (2001) Glucagon-like peptide-1 (7-37) augments insulin release in elderly patients with diabetes. Diabetes Care, 24, 964-5.

54. Best, J.D., Kahn, S.E., Ader, M., Watanabe, R.M., Ni, T.C. and Bergman, R.N. (1996) Role of glucose effectiveness in the determination of glucose tolerance. Diabetes Care, 19, 1018-30.

55. Meneilly, G.S., Elahi, D., Minaker, K.L., Sclater, A.L. and Rowe, J.W. (1989) Impairment of noninsulin-mediated glucose disposal in the elderly. Journal of Clinical Endocrinology and Metabolism, 63, 566-71.

56. Forbes, A., Elliott, T., Tildesley, H., Finegood, D. and Meneilly, G.S. (1998) Alterations in non-insulinmediated glucose uptake in the elderly patient with diabetes. Diabetes, 47, 1915-19.

57. Meneilly, G.S., McIntosh, C.H., Pederson, R.A., Habener, J.F., Gingerich, R., Egan, J.M., Finegood, D.T. and Elahi, D. (2001) Effect of glucagon-like peptide 1 on non-insulin-mediated glucose uptake in the elderly patient with diabetes. Diabetes Care, 24, 1951-6. 
58. Laakso, M., Malkki, M., Kekalainen, P., Kuusisto, J., Mykkanen, L. and Deeb, S.S. (1995) Glucokinase gene variants in subjects with late-onset NIDDM and impaired glucose tolerance. Diabetes Care, 18, 398-400.

59. McCarthy, M.I., Hitman, G.A., Hitchins, M. et al. (1993) Glucokinase gene polymorphisms; a genetic marker for glucose intolerance in cohort of elderly Finnish men. Diabetic Med., 10, 198-204.

60. Obermajer-Kusser, B., White, M.F., Pongratz, D.E. et al. (1989) A defective intramolecular autoactivation cascade may cause the reduced kinase activity of the skeletal muscle insulin receptor from patients with non-insulin-dependent diabetes mellitus. J. Biol. Chem., 264, 9497-504.

61. Hawley, J.A. and Lessard, S.J. (2007) Mitochondrial function: use it or lose it. Diabetologia, 50, 699-702.

62. Barazzoni, R. (2004) Skeletal muscle mitochondrial protein metabolism and function in ageing and type 2 diabetes. Current Opinion in Clinical Nutrition and Metabolic Care, 7, 97-102.

63. Petersen, K.F., Befroy, D., Dufour, S., Dziura, J., Ariyan, C., Rothman, D.L., DiPietro, L., Cline, G.W. and Shulman, G.I. (2003) Mitochondrial dysfunction in the elderly: possible role in insulin resistance. Science, 300, 1140-2.

64. Ritz, P. and Berrut, G. (2005) Mitochondrial function, energy expenditure, aging and insulin resistance. Diabetes Metab., 31, 5S67-5S73.

65. Stepka, M., Rogala, H. and Czyzyk, A. (1993) Hypoglycemia; a major problem in the management of diabetes in the elderly. Aging, 5, 117-21.

66. Lassmann-Vague, L. (2005) Hypoglycemia in elderly diabetic patients. Diabetes Metab., 31, 5S53-5S57.

67. Thomson, F.J., Masson, E.A., Leeming, J.T. and Boulton, A.J. (1991) Lack of knowledge of symptoms of hypoglycaemia by elderly diabetic patients. Age and Aging, 20, 404-6.

68. Meneilly, G.S., Cheung, E. and Tuokko, H. (1994) Counterregulatory hormone responses to hypoglycemia in the elderly patient with diabetes. Diabetes, 43, 403-10.

69. Meneilly, G.S. (1996) Pancreatic polypeptide responses to hypoglycemia in aging and diabetes. Diabetes Care, 19, 544-6. 